\title{
ANALISA FAKTOR-FAKTOR PENYEBAB REWORK DAN TINGKAT KESULITAN PECEGAHANNYA PADA PEKERJAAN STRUKTUR, FINISHING, DAN MEP
}

\author{
Fendy $^{1}$, Andi $^{2}$, Jani Rahardjo 3
}

\begin{abstract}
ABSTRAK: Dalam bidang konstruksi, proses yang harus dilalui untuk menghasilkan produk konstruksi yaitu pekerjaan proyek konstruksi. Salah satu yang dapat menghambat suatu proyek konstruksi yaitu bila terjadi rework dalam proyek konstruksi tersebut. Rework dapat berdampak pada biaya, produktivitas dan waktu pelaksanaan pekerjaan. Penelitian ini berfokus pada frekuensi dan tingkat kesulitan pencegahan dari faktor-faktor penyebab rework sehingga munculnya rework dapat diminimalisir pada proyek konstruksi. Penelitian yang dilakukan yaitu dengan membuat kuesioner yang berkaitan dengan rework serta membagikannya kepada responden yang bekerja sebagai main contractor dan kontraktor MEP di wilayah Surabaya. Pada pekerjaan struktur dan finishing faktor perubahan desain menjadi faktor yang paling sering terjadi dan paling sulit dicegah agar tidak terjadi rework. Pada pekerjaan MEP faktor jadwal proyek terlalu padat paling sering muncul dan faktor yang paling sulit dicegah untuk menghindari rework adalah faktor kurangnya modal kerja dari pemilik.
\end{abstract}

Kata kunci : rework, frekuensi, tingkat kesulitan pencegahan

\begin{abstract}
In the field of construction, the process that must be passed to produce construction products is construction project work. One that can hinder a construction project is when there is rework in the construction project itself. Rework can impact on cost, productivity and execution time. This study focuses on the frequency and level of difficulty prevention from the causative factors of rework so that the effect of rework can be minimized in the construction projects. The research is proceed by making questionnaires related to rework and distributing them to respondents who work as main contractor and MEP contractor in Surabaya area. In structural and finishing work the factor of design changing becomes the most frequent ad the most difficult factor to prevent rework. On the MEP work the factor of too dense project schedule is the most often appear and the most difficult factor to prevent to avoid rework is the factor of lack of working capital from the owner.
\end{abstract}

Keywords: rework, frequency, level of difficulty prevention

\footnotetext{
${ }^{1}$ Mahasiswa Program Studi Magister Teknik Sipil Universitas Kristen Petra, shadowaa8@gmail.com

${ }^{2}$ Dosen Program Studi Magister Teknik Sipil Universitas Kristen Petra, andi@petra.ac.id

${ }^{3}$ Dosen Program Studi Magister Teknik Sipil Universitas Kristen Petra,jani@petra.ac.id
} 


\section{PENDAHULUAN}

Rework merupakan salah satu yang sering terjadi dalam sebuah proyek konstruksi. Terjadinya rework dapat menyebabkan banyak dampak pada pekerjaan konstruksi baik dari segi kinerja, produktivitas, waktu, dan biaya. Beberapa penelitian telah mengungkapkan bahwa biaya yang ditimbulkan akibat timbulnya rework sangat signifikan. Biaya rework dalam proyek konstruksi antara 5\% hingga 20\% dari nilai kontrak (Burati et al, 1992; Barber et al, 2000). Biaya yang diperlukan untuk memperbaiki masalah kualitas adalah $12,4 \%$ dari nilai kontrak (Burati et al, 1992). Menururt Love (2002) biaya langsung yang timbul akibat rework adalah sebesar $15 \%$ dari nilai kontrak. Menurut Love (2010) biaya yang timbul akibat rework pada proyek infrastruktur adalah sebesar $10 \%$ dari nilai kontrak.

Mengurangi rework secara luas pada proyek konstruksi dianggap sebagai cara efektif untuk meningkatkan kinerja pembangunan dalam hal produktivitas, biaya, dan waktu (Zhang et al, 2012). Dengan mengetahui faktor penyebab rework yang paling sering terjadi dan paling sulit dicegah agar tidak terjadi rework diharapkan munculnya rework dapat diminimalisir pada pekerjaan-pekerjaan tersebut.

\section{TINJAUAN PUSTAKA}

\subsection{Definisi Rework}

Rework secara umum dapat diartikan sebagai mengolah lagi, mengerjakan ulang, dan akan seterusnya dipakai. Beberapa peneliti mendefinisikan rework menurut pandangan dan pendapat mereka masing-masing. Beberapa definisi rework adalah sebagai berikut.

- Rework adalah efek yang tidak perlu dari mengerjakan ulang suatu proses atau aktivitas yang diimplementasikan secara tidak tepat pada awalnya dan dapat ditimbulkan oleh kesalahan ataupun adanya variasi (CIDA, 1995).

- Rework kegiatan yang harus dilakukan lebih dari sekali atau kegiatan yang membuang pekerjaan yang sebelumnya dikerjakan sebagai bagian dari proyek (Rogge et al, 2001).

- Rework adalah total biaya langsung untuk mengulangi pekerjaan di lapangan tanpa memulai penyebab (COAA, 2001).

- Rework adalah dampak yang tidak perlu dari mengulangi proses atau kegiatan yang dilakukan dengan tidak tepat saat dilaksanakan pertama kalinya (Love, 2002).

- Rework adalah pekerjaan ditemukan untuk dilakukan perubahan (baik melalui kesalahan, kelalaian atau peraturan perubahan) (Taylor, 2008).

\subsection{Faktor-Faktor Penyebab Rework}

Proyek konstruksi merupakan proyek yang melibatkan banyak pihak dan terjadi banyak proses yang kompleks sehingga setiap proyek adalah unik adanya. Oleh karena itu, faktorfaktor yang dapat menyebabkan rework pada proyek konstruksi sangat banyak dan bervariasi, diantaranya adalah faktor-faktor pada Tabel 1.

\section{METODOLOGI PENELITIAN}

Penelitian ini dimulai dengan mempelajari literatur-literatur yang berhubungan dengan rework. Selanjutnya pengumpulan data dilakukan dengan menyebar kuesioner dengan cara mendatangi satu per satu pada perusahaan kontraktor utama dan kontraktor MEP yang berada di Surabaya. Pada kesempatan ini pula dilakukan wawancara dengan pihak terkait dengan tujuan menggali menggali lebih dalam tentang frekuensi dan tingkat kesulitan pencegahan faktor penyebab rework dari masing - masing responden dengan lebih mendalam. Setelah itu data akan dianalisa dengan bantuan program SPSS berupa analisa anova dan analisa IPA (Importance Performance Analysis). 
Tabel 1. Faktor-Faktor Penyebab Rework

\begin{tabular}{|c|c|}
\hline Faktor Penyebab Rework & Indikator \\
\hline \multirow{5}{*}{ Desain dan Dokumentasi } & Perubahan desain \\
\hline & Detail gambar tidak jelas \\
\hline & Kesulitan pelaksanaan dilapangan \\
\hline & $\begin{array}{l}\text { Kekurangan pengetahuan konsultan tentang karakter } \\
\text { bahan }\end{array}$ \\
\hline & Kesalahan desain \\
\hline \multirow{3}{*}{$\begin{array}{l}\text { Perencanaan dan } \\
\text { Penjadwalan }\end{array}$} & Jadwal proyek yang terlalu padat \\
\hline & Kurangnya modal kerja dari pemilik \\
\hline & Perubahan fungsi proyek \\
\hline \multirow{6}{*}{ Material dan Peralatan } & Cacat material \\
\hline & Material terkirim salah \\
\hline & Material terlambat \\
\hline & Material tidak berada ditempat yang dibutuhakan \\
\hline & Penggantian mateiral / peralatan selama pembanguan \\
\hline & Kurangnya peralatan yang memadai \\
\hline \multirow{6}{*}{ Sumber Daya Manusia } & Kurangnya pelatihan pada pekerja \\
\hline & Kurangnya motivasi pekerja \\
\hline & Pekerja kurang berpengalaman \\
\hline & Banyaknya kerja lembur \\
\hline & Salah prosedur kerja \\
\hline & Kesalahan dan kelalaian pekerja \\
\hline \multirow{10}{*}{$\begin{array}{l}\text { Kepemimpinan dan } \\
\text { Komunikasi }\end{array}$} & $\begin{array}{l}\text { Komunikasi yang tidak efektif antara konsultan } \\
\text { pengawas dan kontraktor }\end{array}$ \\
\hline & $\begin{array}{l}\text { Komunikasi yang tidak efektif antara konsultan } \\
\text { kontraktor dan pekerja }\end{array}$ \\
\hline & Koordinasi yang buruk antar kontraktor \\
\hline & $\begin{array}{l}\text { Banyaknya subkon / DC / kontraktor yang terlibat } \\
\text { dalam proyek }\end{array}$ \\
\hline & $\begin{array}{l}\text { Proses pengambilan keputusan yang buruk dari } \\
\text { kontraktor }\end{array}$ \\
\hline & Proses pengambilan keputusan yang buruk dari owner \\
\hline & Kurannya informasi lapangan \\
\hline & Kurangnya manajemen kontraktor di proyek \\
\hline & $\begin{array}{l}\text { Kurangnya peran pemilik / pembeli dalam } \\
\text { pembangunan }\end{array}$ \\
\hline & Kurangnya komitmen kerja QC kontraktor \\
\hline \multirow{5}{*}{ Instruksi dan Inspeksi } & Monitoring buruk dari kontraktor \\
\hline & Monitoring buruk dari pengawas proyek \\
\hline & Instruksi yang tidak jelas dari konsultan perencana \\
\hline & Instruksi yang tidak jelas dari pengawas proyek \\
\hline & Instruksi yang tidak jelas dari owner \\
\hline \multirow{2}{*}{ Engineering } & Perubahan lingkup pekerjaan \\
\hline & Kontrol dokumentasi yang buruk dari kontraktor \\
\hline \multirow{3}{*}{ Lingkungan Luar } & Kurangnya antisipasi terdapat keadaan alam \\
\hline & Kondisi lapangan yang buruk (air, listrik, telepon) \\
\hline & Gangguan warga sekitar proyek \\
\hline Kontrak & $\begin{array}{l}\text { Ketidakjelasan ruang lingkup pekerjaan pada dokumen } \\
\text { kontrak (spesifikasi material) }\end{array}$ \\
\hline
\end{tabular}

Sumber : Fayek et al. (2004) ; Winata et al. (2005) ; Hwang et al. (2009) ; Zhang et al. (2012) ; Chundawan et al. (2014) ; Ye et al. (2014) 


\section{ANALISIS DAN PEMBAHASAN}

\subsection{Gambaran Umum Obyek Penelitian}

Objek pada penelitian yang dilakukan adalah responden yang bekerja pada perusahaan kontraktor udatama dan kontraktor MEP. Kuesioner disebarkan kepada pihak terkait sejak bulan Maret 2017 hingga Mei 2017. Selama survei dilakukan, peneliti telah berhasil mendapatkan sebanyak 72 kuesioner dari 100 kuesioner yang disebarkan.

\subsection{Frekuensi dan Tingkat Kesulitan Pecegahan dari Faktor Penyebab Rework}

Berdasarkan Gambar 1. Faktor yang mendapatkan nilai frekuensi tertinggi pada pekerjaan struktur dan finishing adalah faktor perubahan desain dengan nilai rata-rata 4,38 . Sedangkan pada pekerjaan MEP faktor yang mendapatkan nilai frekuensi tertinggi adalah faktor jadwal proyek terlalu padat dengan nilai rata-rata 3,75. Pada Tabel 2. Berdasarkan hasil uji anova perbedaan frekuensi antara pekerjaan struktur, finishing, dan MEP menunjukkan terdapat 6 faktor yang mendapatkan nilai $p$ value $\leq 0,05$ sehingga terdapat perbedaan frekuensi antara pekerjaan struktur, finishing, dan MEP pada faktor-faktor tersebut.

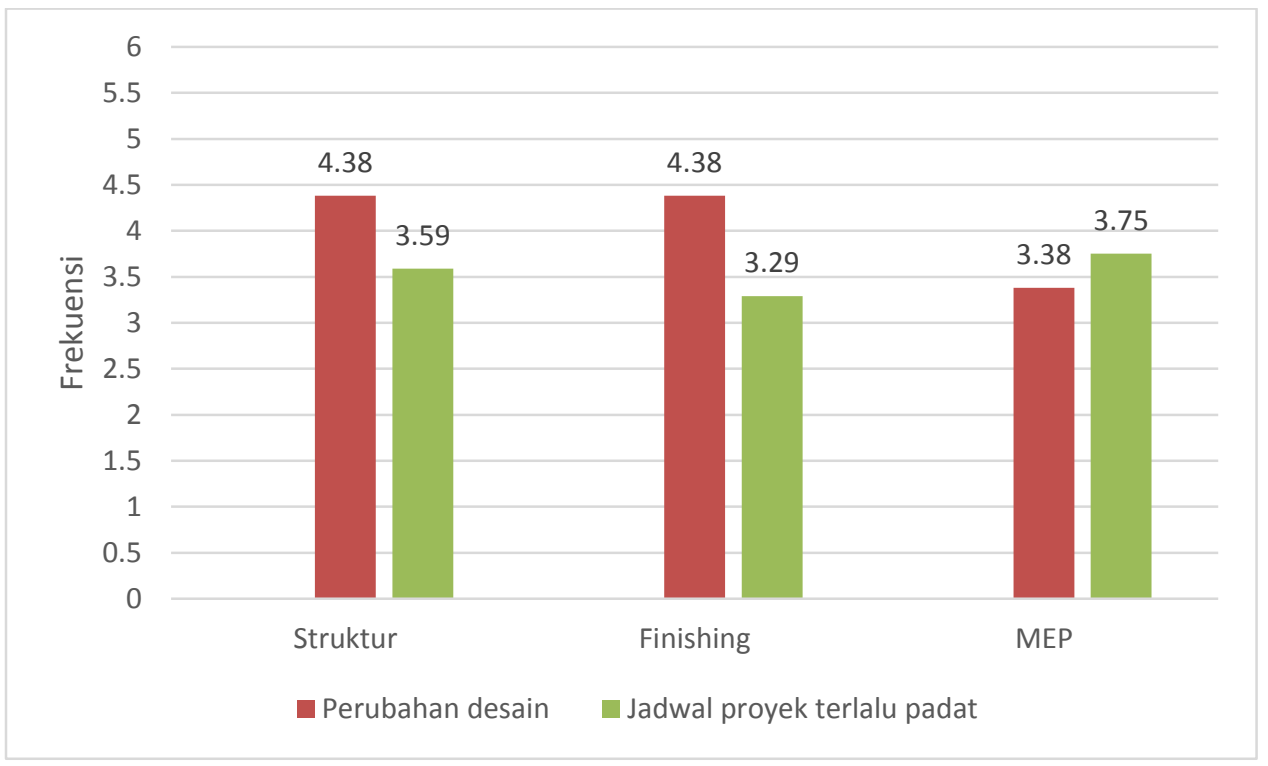

Gambar 1. Faktor-Faktor Penyebab Rework yang Mendapatkan Nilai Rata-Rata Frekuensi Terbesar

Tabel 2. Uji Stististik Anova Perbedaan Frekuensi pada Pekerjaan Struktur, Finishing, dan MEP

\begin{tabular}{|c|l|c|c|}
\hline No & \multicolumn{1}{|c|}{ Faktor Penyebab Rework } & P value & Keterangan \\
\hline 1 & Perubahan desain & 0.006 & Signifikan \\
\hline 2 & Detail gambar tidak jelas & 0.002 & Signifikan \\
\hline 3 & Kesulitan pekerjaan dilapangan & 0.029 & Signifikan \\
\hline 4 & Perubahan fungsi proyek & 0.013 & Signifikan \\
\hline 5 & Cacat material & 0.001 & Signifikan \\
\hline 6 & Banyaknya kerja lembur & 0.026 & Signifikan \\
\hline
\end{tabular}


Pada Gambar 2. menunjukkan bahwa faktor yang mendapatkan nilai tingkat kesulitan pencegahan terbesar pada pekerjaan struktur dan finishing adalah faktor perubahan desain. Sementara pada pekerjaan MEP faktor yang mendapatkan nilai tingkat kesulitan pencegahan adalah faktor kurangnya modal kerja dari pemilik, dimana baik pihak kontrakor utama dan kontraktor MEP merasa bahwa kesalahan atau perubahan yang terjadi akibat pihak lain adalah hal yang mereka sulit untuk cegah agar tidak terjadi rework. Berdasarkan Tabel 3. menunjukkan terdapat 4 faktor pennyebab rework yang mendapatkan hasil $p$ value $\leq 0,05$ sehingga pada faktor-faktor tersebut terdapat perbedaan tingkat kesulitan pencegahan antara pekerjaan struktur, finishing, dan MEP.

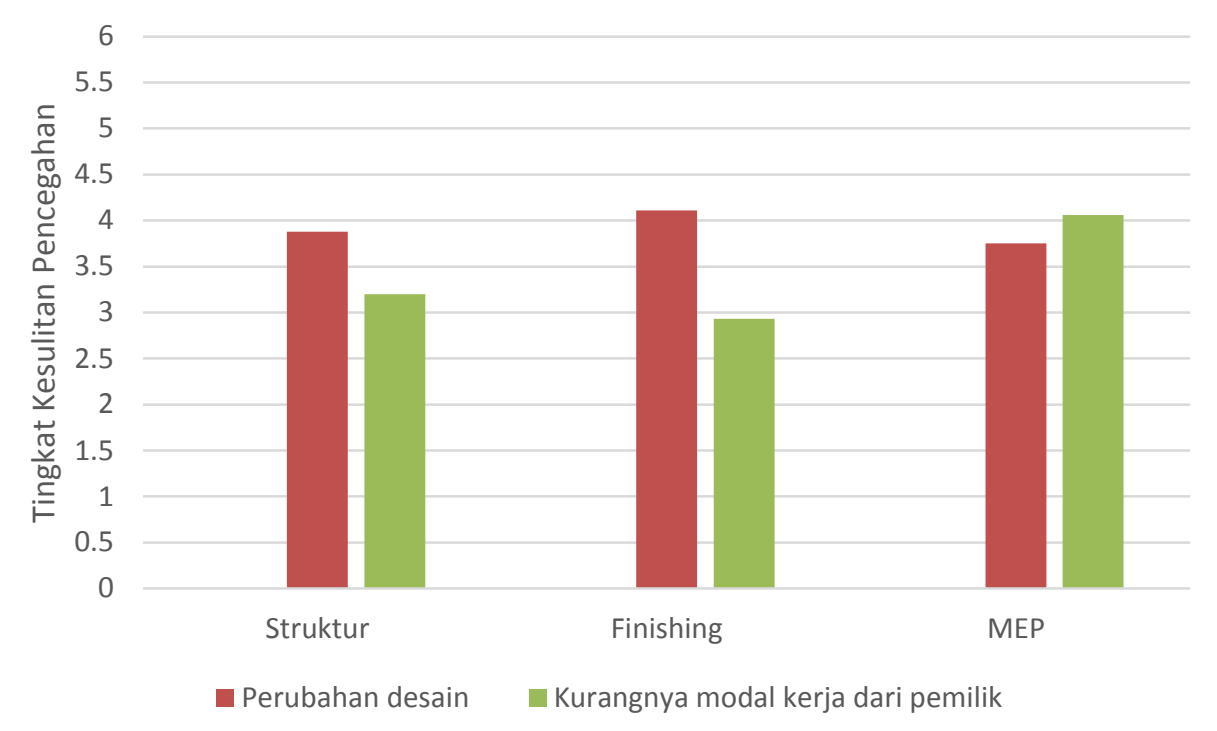

Gambar 2. Faktor-Faktor Penyebab Rework yang Mendapatkan Nilai Rata-Rata Tingkat Kesulitan Pencegahan Terbesar

Tabel 3. Uji Stististik Anova Perbedaan Tingkat Kesulitan Pencegahan pada Pekerjaan Struktur, Finishing, dan MEP

\begin{tabular}{|c|l|c|c|}
\hline No & Faktor Penyebab Rework & P value & Keterangan \\
\hline 1 & Detail gambar tidak jelas & 0.001 & Signifikan \\
\hline 2 & Kurangnya modal kerja dari pemilik & 0.042 & Signifikan \\
\hline 3 & Kurangnya peralatan yang memadai & 0.048 & Signifikan \\
\hline 4 & Kurangnya pelatihan pada pekerja & 0.01 & Signifikan \\
\hline
\end{tabular}

\subsection{Pengelompokan Faktor Penyebab Rework}

Pada Tabel 4. Menujukkan bahwa pada pekerjaan struktur dan finishing faktor perubahan desain dan faktor detail gambar tidak jelas merupakan faktor yang paling harus diperhatikan oleh pihak kontraktor utama dikarenakan faktor tersebut mendapatkan nilai frekuensi dan tingkat kesulitan pencegahan yang tinggi sehingga kedua faktor tersebut harus menjadi perhatian khusus sehingga dapat mencegah peluang terjadinya rework. Sedangkan pada pekerjaan MEP meskipun tidak ada faktor yang mendapatkan nilai besar pada frekuensi dan tingkat kesulitan pencegahan namun faktor perubahan desain dan faktor kurangnya modal kerja dari pemilik adalah faktor yang paling harus diperhatikan oleh pihak kontraktor MEP. Meskipun memilik frekuensi yang tidak terlalu besar namun kedua faktor tersebut mempunyai nilai tingkat kesulitan pencegahan yang besar sehingga perlu diperhatikan oleh pihak kontraktor MEP. 
Tabel 4. Faktor Penyebab Rework yang Menjadi Prioritas Tertinggi pada Pekerjaan Struktur dan Finishing

\begin{tabular}{|c|l|c|c|}
\hline No & \multicolumn{1}{|c|}{ Faktor Penyebab Rework } & $\begin{array}{c}\text { Rata-Rata } \\
\text { Frekuensi }\end{array}$ & $\begin{array}{c}\text { Rata-Rata Tingkat } \\
\text { Kesulitan Pencegahan }\end{array}$ \\
\hline 1 & Perubahan desain & 4.38 & 3.99 \\
\hline 2 & Detail gambar tidak jelas & 4.12 & 3.78 \\
\hline
\end{tabular}

Tabel 5. Faktor Penyebab Rework yang Menjadi Prioritas Tertinggi pada Pekerjaan MEP

\begin{tabular}{|c|l|c|c|}
\hline No & \multicolumn{1}{|c|}{ Faktor Penyebab Rework } & $\begin{array}{c}\text { Rata-Rata } \\
\text { Frekuensi }\end{array}$ & $\begin{array}{c}\text { Rata-Rata Tingkat } \\
\text { Kesulitan Pencegahan }\end{array}$ \\
\hline 1 & Perubahan desain & 3.38 & 3.75 \\
\hline 2 & Kurangnya modal kerja dari pemilik & 2.88 & 4.06 \\
\hline
\end{tabular}

\subsection{Pekerjaan Konstruksi yang Paling Sering Terjadi Rework}

Berdasarkan Tabel 6. Menujukkan bahwa pada pekerjaan finishing paling sering terjadi rework dibandingkan dengan pekerjaan sturktur dan pekerjaan MEP. Hal ini menunjukkan bahwa pada pekerjaan finishing perlu mendapatkan perhatian khusus pada pekerjaan konstruksi sehingga dapat mengurangi kemungkinan terjadinya rework.

Tabel 6. Pekerjaan Konstruksi yang Sering Terjadi Rework

\begin{tabular}{|c|l|c|}
\hline No & \multicolumn{1}{|c|}{ Pekerjaan Konstruksi } & Rata-Rata \\
\hline 1 & Pekerjaan Struktur & 3.04 \\
\hline 2 & Pekerjaan Finishing & 3.82 \\
\hline 3 & Pekerjaan MEP & 3.63 \\
\hline
\end{tabular}

\section{KESIMPULAN DAN SARAN}

Berdasarkan hasil pengolahan data dalam penelitian ini dapat ditarik kesimpulan sebagai berikut :

- Faktor yang memiliki frekuensi tertinggi pada pekerjaan struktur dan finishing adalah perubahan desain sedangkan ada pekerjaan MEP adalah jadwal proyek terlalu padat.

- Faktor yang paling sulit dicegah pada pekerjaan struktur dan finishing adalah perubahan desain sedangkan pada pekerjaan MEP adalah pengambilan keputusan yang buruk dari owner.

- Pada pekerjaan struktur dan finishing faktor yang menjadi prioritas utama adalah faktor perubahan desain dan detail gambar tidak jelas.

- $\quad$ Pada pekerjaan MEP faktor yang menjadi prioritas utama adalah faktor perubahan desain dan kurangnya modal kerja dari pemilik.

- $\quad$ Pekerjaan yang paling sering terjadi rework adalah pekerjaan finishing.

Untuk penelitian selanjutnya, ada baiknya dilakukan penelitian yang lebih mendalam mengenai faktor-faktor penyebab rework pada pekerjaan struktur, finishing, dan MEP berdasarkan pandangan dari pihak-pihak lain seperti owner, konsultan perencana, dan juga konsultan pengawas (MK). Hal ini bertujuan agar faktor-faktor penyebab rework dapat diketahui lebih jelas dari pandangan berbagai pihak. 


\section{DAFTAR PUSTAKA}

Burati, J. L., Farrington, J. J., and Ledbetter, J. B. (1992). "Causes of Quality Deviations in Design and Construction." Journal of Construction Engginering and Management, 10.1061/(ASCE)0733-9364(1992)118:1(34), 34-39

Chundawan, E., Alifen, R. S. (2014). "Model Sumber dan Penyebab Rework pada Tahapan Proyek Konstruksi." Civil Engineering Dimension, Vol 1, No. 1

CIDA. (1995). "Measuring up pr Muddling Tough: Best Practice in The Australian NonResidential Construction Industry", Development Agency and Masters Builders Australia, Sydney Australia, pp.59-63.

COOA. (2001). "Field Rework Committee Meeting Minutes, 28 September 2001." Construction Owners Association of Alberta (COAA), Edmonton, Alta.

Fayek, A. R., Dissanayake, M., Campero, O. (2004) "Developing a Standard Methodology for Measuring and Classifying Construction Field Rework." Canadian Journal of Civil Engineering. 31: 1077-1089.

Hwang, B., Thomas, S. R., Haas, C. T., and Caldas, C. H. (2009). "Measuring The Impact of Rework on Construction Cost Performance." Journal of Construction Enginering and Management, 135, 187-198.

Love, P. E. D., Edwards, D. J., Watson, H., and Davis, P. (2010). "Rework in Civil Infracstructure Projects : Determiantion of Cost Predictior." Journal of Construction Enginering and Management, 136, 275-282.

Love, P. E. D. (2002). "Influence of Project Type and Procurement Method on Rework Cost in Building Construction Projects." Journal of Construction Enginering and Management, 128, 18-29.

Rogge, D. F., Cogliser, C., Alaman, H., and McCormack, S. (2001). "An Investigation of Field Rework in Industrial Construction", Construction Industry Institute, Austin, TX.

Taylor, T., and Ford, D. (2008). "Managing Tipping Point Dynamics in Complex Construction Projects." Journal of Construction Enginering and Management, 10.1061/(ASCE) 07339364(2008)134:6(421), 421-431.

Winata, S., Hendralim, Y., Andi. (2005) "Faktor-Faktor Penyebab Rework pada Pekerjaan Konstruksi." Civil Engineering Dimension, Vol 7, No. 1, 22-29.

Zhang, D., Haas, C. T., Goodrum, P. M., Carlos, H. C., and Robin, G. (2012). "Construction Small-Project Rework Reduction for Capital Facilities." Journal of Construction Enginering and Management, 138, 1377-1385.

Ye, G., Jin, Z., Xia, B., and Martin. (2014). "Analyzing Causes for Reworks in Construction Projects in China." Journal of Construction Enginering and Management, 04014097. 